\title{
Modeling of concrete dwellings based on results from ambient vibration tests
}

\section{Abstract}

Based on both ambient vibration measurements and numerical models using the wide-column analogy and the finite element method, vibrations periods of low-rise concrete dwellings are estimated in this study. A brief review of parametric and nonparametric techniques is presented and discussed, and in-situ measurements techniques are critically compared. The results of ambient vibration tests are used to calibrate numerical models. Advantages, drawbacks and accuracy of parametric techniques, as well as particular recommendations to build numerical models for assessing the elastic behavior of low-rise concrete wall dwellings, are proposed.

\section{Keywords}

Ambient vibration, modeling, finite element, wide-column analogy, concrete wall dwelling.

\author{
Julian Carrillo* \\ Giovanni González \\ Astrid Rubiano \\ Department of Civil Engineering, Universidad \\ Militar Nueva Granada, UMNG. Cr. 11 No. \\ 101-80, Bogotá, Colombia. \\ Received in 29 Apr 2013 \\ In revised form 25 Jun 2013 \\ ${ }^{*}$ Author e-mail: wjcarrillo@gmail.com
}

\section{INTRODUCTION}

Nonlinear dynamic analysis of very short period structures indicate that these structures have probabilities of collapse that are much higher than that of longer period structures, even though the short and long period buildings are designed under the same design rules (Charney et al., 2012). For instance, most of current equations proposed for determining the fundamental period of vibration of concrete buildings have been developed using data from frame structures or from medium- or highrise concrete wall buildings. Unfortunately, data from very low-rise buildings (i.e., single- and twostory dwellings) is scarce to calibrate a similar equation.

One of the main needs for the development of a rational approach to the earthquake resistant design of buildings is the ability to predict accurately their dynamic characteristics. The first and most fundamental step in achieving this objective is to correlate measured and calculated results (Ward, 1977). There are now numerous experimental techniques that can be used to assist in this process. The ambient vibration technique for testing full-scale structures is based on small-level excitations. This technique may be used to determine many mode shapes and frequencies of vibration and the corresponding damping values, with adequate accuracy for most purposes. Knowledge 
of these properties is essential to understand and interpret structural response during strong earthquake motion, during wind excitation and to compare observations with theoretical results. Many modern dynamic studies, although aimed at acquiring information that would assist in the design of earthquake resistant structures, are still based on the linear theory of elasticity. Hence, the results of small-amplitude vibrations can be used to check and improve various assumptions involved in constructing dynamical models of structures (Trifunac, 1972).

The aims of this study are to characterize the fundamental periods of vibration of low-rise concrete wall dwellings built according to the design rules of common practice in Latin America, and to demonstrate the utility of in-situ techniques to complement and improve numerical modeling. The periods of vibration of the dwellings were assessed using non-parametric and parametric estimation techniques, that is, ambient vibration records and numerical models, respectively. The ambient vibration measurements on the dwellings were useful to determine the first and second modes of the structures. These results were used to calibrate numerical models. This paper is divided into three main sections. In the first section, a brief review of parametric and non-parametric techniques is presented and discussed, and in-situ measurements techniques are critically compared. The second section is devoted to the experimental program, where four tested structures, ambient vibration tests and numerical modeling are described. Ambient vibration tests are shown in terms of measuring equipment, experimental setup and data processing. Numerical modeling deals with both the models obtained from finite element method and wide-column analogy, and the material properties of the dwellings studied. In the third section, the experimental and computed results obtained on dwellings are compared and discussed.

\section{TECHNIQUES FOR ASSESSING THE DYNAMIC PROPERTIES OF STRUCTURES}

The dynamic parameters of a structure may be useful to calibrate its elastic properties for numerical modeling, to assess the benefit of retrofitting, to detect the modification of its behavior after damage, to quantify the damage after earthquakes, and to determine or predict its behavior under earthquakes.

The linear dynamic behavior can be fully described by the modal parameters such as resonance frequencies, modal shapes and damping ratios. These parameters mainly depend on the story masses, which remain unchanged whatever the damage stage of the structure, and the story stiffness, which is influenced by the structural modifications such as reinforcing and damage. Story stiffness can be also representative of the quality of the material (e.g. the modulus of elasticity of the cracked or undamaged concrete) and of the structural design (e.g. irregularity of the shear resistance or soft story). The ratio between transverse and longitudinal frequencies can, for example, provide information on the relative stiffness in perpendicular directions that may expose a lack of stiffness and may help in structural design understanding. Comparing the frequencies and mode shape before and after shaking allows the evaluation of damage. This method requires knowledge of the initial state of the structure in such a way that the modification due to damage can be observed (Michel et al., 2008).

There are many different techniques to identify the "natural" modes of a structure, which can be divided into non-parametric and parametric methods. In the first category, the methods provide information about the modal parameters of a structure that we can extract using modal analysis 
methods based on signal processing tools. In the second category, the parameters of the considered structure are updated within a numerical model to fit the recorded data in frequency or in the time domain. Non-parametric methods are usually more user-friendly and easier to implement than parametric techniques (Michel et al., 2008).

\subsection{Non-parametric techniques}

Non-parametric techniques are in-situ testing methods that consist in recording the responses of the structure on the bandwidth $0-50 \mathrm{~Hz}$ with synchronized transducers such as accelerometers. In addition to usefulness of knowing the dynamic properties of a structure, data recorded during nonparametric techniques allow model updating, that is, the calibration of numerical and analytical modeling (Michel et al., 2008). Testing real structures offers the possibility to analyze phenomena that are difficult to reproduce in idealized laboratory experiments. In counterpart, the tested structures are only partially known and the range of loading is limited (Hans et al., 2005).

In order to identify the dynamic characteristics of the structures, different in-situ testing techniques can be used depending on type and location of the structures, requested range of motion amplitude and available economic resource. In seismic areas, the structures can be instrumented to record their response to a seismic input; however, this requires earthquake occurrence to gather data. Therefore, in the past 50 years alternative techniques have been proposed to evaluate the dynamic behavior of buildings. On an existing structure in the field, three different types of excitation are used: shocks or impact action where a heavy mechanical device impacts the upper part of the structure and causes a short impulsive (transient), harmonic forcing induced by oscillator or mechanical shaker (sinusoidal) at the top of the structure, and ambient vibrations (random). Results reported by Trifunac (1972) strongly suggest that, in the linear range of excitation, test based on ambient vibrations give essentially the same results that those that would be obtained from the forced vibration experiments. In addition, during the last two decades, the use of ambient vibrations for modal analysis has increased as compared to forced vibrations because of their low cost. Because of its low cost, the ambient vibration method is also well adapted to large-scale analysis for which a large set of buildings has to be analyzed (Michel et al., 2008).

Table 1 shows the horizontal accelerations recorded by different researchers during in-situ testing of structures. Table demonstrates that accelerations measured during shock and forced vibration tests are around 10 times and 100 times, respectively, than those measured during ambient vibration tests. In all cases, the acceleration amplitudes are small enough not to move the structure's response beyond its elastic domain. However, ambient noise technique shows the lower costs and greater simplicity (Hans et al., 2005).

Latin American Journal of Solids and Structures 11 (2014) 488 - 503 
Table 1 Horizontal accelerations recorded during in-situ testing.

\begin{tabular}{ccccc}
\hline \hline \multirow{2}{*}{ Author } & Measured & \multicolumn{3}{c}{ Type of vibration } \\
\cline { 3 - 5 } & at: & Shock & Forced & Ambient \\
\hline Hans et al. & Top & $10^{-2} \mathrm{~g}$ & $10^{-3} \mathrm{~g}$ & $10^{-4} \mathrm{~g}$ \\
$(2005)$ & Bottom & --- & $10^{-4} \mathrm{~g}$ & $10^{-5} \mathrm{~g}$ \\
\hline Michael et & Top & --- & --- & $10^{-1}$ to $10^{-4} \mathrm{~g}$ \\
al. (2008) & Bottom & --- & --- & --- \\
\hline Ditommaso & Top & $10^{-2} \mathrm{~g}$ & $10^{-4}$ to $10^{-3} \mathrm{~g}$ & $10^{-5} \mathrm{~g}$ \\
et al. (2010) & Bottom & ---- & --- & --- \\
\hline \hline
\end{tabular}

Ambient vibration testing (AVT) is normally carried out by just measuring the responses under ambient or operational conditions, in other words, without the needs for artificial-induced loading. Ambient vibrations are produced by natural forces derived from local atmospheric conditions (wind) and spread along the structure, by forces related to the ground shaking (seismic ambient noise, traffic-induced vibrations), and by internal forces (factories, human occupancy/activities). In some places, the amplitude of structural motion of ambient vibrations depends mainly on wind speed, since wind is a more effective exciting source than ground microtremors or sources in the structure (Trifunac, 1972).

Recording ambient vibrations at different points of a civil engineering structure (e.g. bridge, building or houses) allows the determination of its modes and frequencies of vibration through operational modal analysis techniques. Modern technologies also allow to perform, in a short time (10$15 \mathrm{~min}$ ), an assessment of the translational dynamic properties of a single building with ambient noise and thus, to study a large number of constructions with a limited effort. In general, the simplicity of instrumentation set-up, the reduced amount of both data, the reduced amount of time and money resources required, and the wide range of potential applications are the main advantages that support why their use is wide-spread today (Michel et al., 2008; Ditommaso et al., 2010).

However, De Biasio et al. (2012) state that the dynamic properties coming from in-situ modal analysis should be treated with caution because these measurements tend to overestimate the natural frequencies. The behavior of the structure under weak (i.e. ambient vibrations) or strong (i.e. earthquakes) excitation could be very different if some of the components has very early stiffness deterioration or non-linear behavior under low imposed load, as it is the case for the low-rise and lightly-reinforced walls for dwellings. In such cases, if a linear technique (i.e. spectral analysis) is used to estimate the seismic behavior of the building, the true natural frequencies may be the noteworthy decreased. This could change significantly the seismic response of the structure and the determination of its performance point.

\subsection{Parametric techniques}

One of the major difficulties in the dynamic response assessment of existing buildings is the lack of available data such as quality of the materials, structural plans, ageing and structural integrity. In such cases, the classical tools in earthquake engineering may turn out to be very expensive. Models based on the modal values, from the simplest analytical model to the most comprehensive finite- 
element model, can be used in evaluating the deformation that occurs in buildings during low and moderate earthquakes. These simulations can be the linear starting point of a more extensive analysis of the non-linear response for earthquake-resistant design (Michel et al., 2010).

To fit the recorded data during in-situ testing of this study, the parameters of the considered dwellings are updated within a numerical model. The finite element method (FEM) has become a robust modeling option for analyzing concrete walls structures. In addition, wide-column analogy (WCA) is commonly used for analysis of shear wall buildings. In this method, wall or wall segments are idealized as artificial columns at the wall centroidal axis. Wall properties are assigned to those artificial columns. Frames are then formed by joining artificial columns to "rigid beams" enclosed within the wall length.

\section{EXPERIMENTAL PROGRAM}

In order to identify the periods of vibration of the three-dimensional prototype dwelling, the two identification methodologies were used. Parametric techniques where a mathematical model is build and the structural parameters needed for producing a good correlation between measured and calculated response are then estimated, were used. Also, a non-parametric technique based on conventional spectral analysis of ambient vibration test (AVT) was applied. AVT was carried out in three single-story dwellings only, because two-story prototypes were not available to be tested. However, measured results were essential to calibrate mathematical models not only of single-story but also of two-story dwellings. Both identification methodologies were also used to validate the applicability of parametric techniques for modeling of low-rise concrete wall dwellings. This section briefly shows and discusses both the main structural characteristics of the tested dwellings, and the experimental setup and data processing of the in-situ method used in this study.

\subsection{Description of tested structures}

In this subsection, we describe the four tested dwellings. The experimental program was designed based on prototype dwellings whose characteristics are similar to those found in most low-rise concrete dwellings in some Latin American countries. This type of construction is made of single- or two-story units built with thin (100-mm thick) reinforced concrete (RC) walls in two orthogonal directions. The floor system consists of $100-\mathrm{mm}$ thick solid slabs which are cast monolithically with walls. Inter-story height is $2.4 \mathrm{~m}$ with a floor plan area varying between 35 and $65 \mathrm{~m}^{2}$. Shallow foundations are strip footings made of 400-mm RC square beams that support a 100-mm thick floor slab.

Two-story dwelling

The floor plan of the two-story dwelling is given in Figure 1a. The floor plan is labeled as prototype $\mathrm{P}-1-2$, that is, the prototype 1 with 2 -story. The overall dimensions of the dwelling are $10.5 \mathrm{~m} \times 6$ $\mathrm{m}$, and the floor plan area is $50 \mathrm{~m}^{2}$. The dwelling has $3.1 \%$ shear walls in $\mathrm{X}$ direction and $5.3 \%$ shear walls in Y direction. The wall density was deduced from the plan. Prototype P-1-2 is separated from adjacent dwellings by $3 \mathrm{~cm}$ gaps filled with polystyrene that runs only over a small part of the longitudinal facade.

Latin American Journal of Solids and Structures 11 (2014) 488 - 503 

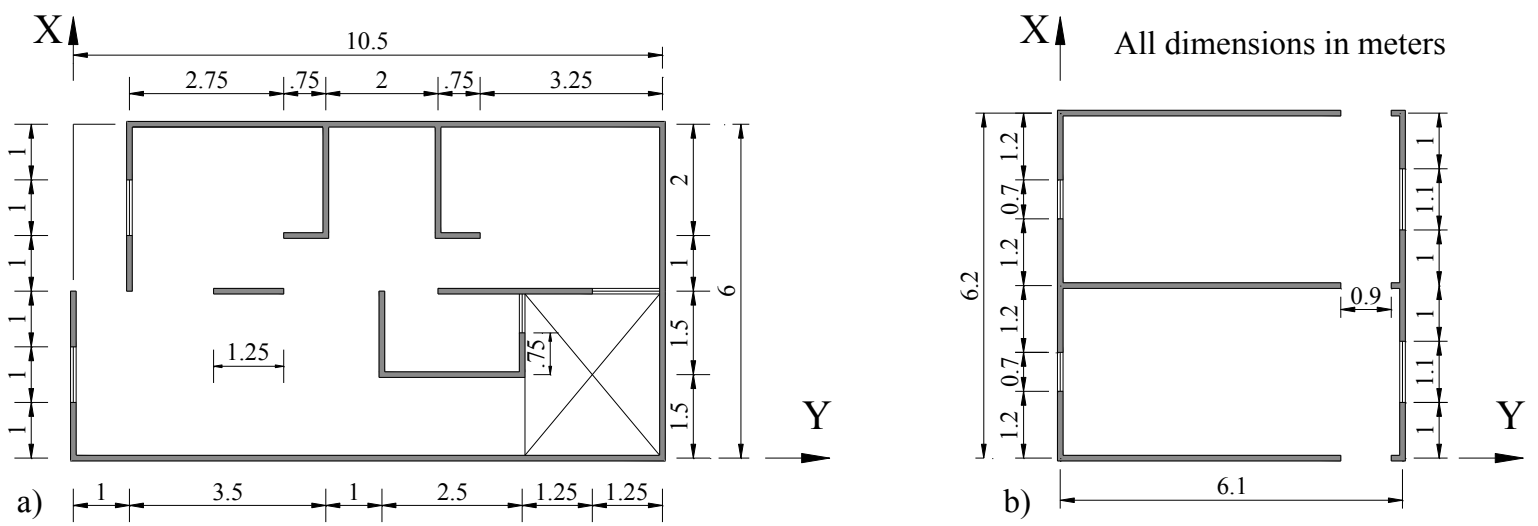

Figure 1 Plan of walls distribution (all dimensions in meters): (a) P-1-1 and P-1-2, (b) P-2-1.

\section{Single-story dwellings}

Three single-story dwellings were assessed. The prototype P-1-1 had the same structural layout at the ground story of the two-story prototype dwelling P-1-2 (see Figure 1a). Layout of prototype P1-1 is shown in Figure 2a. Similarly to prototype P-1-2, P-1-1 is separated from adjacent dwellings by $3 \mathrm{~cm}$ gaps filled with polystyrene.
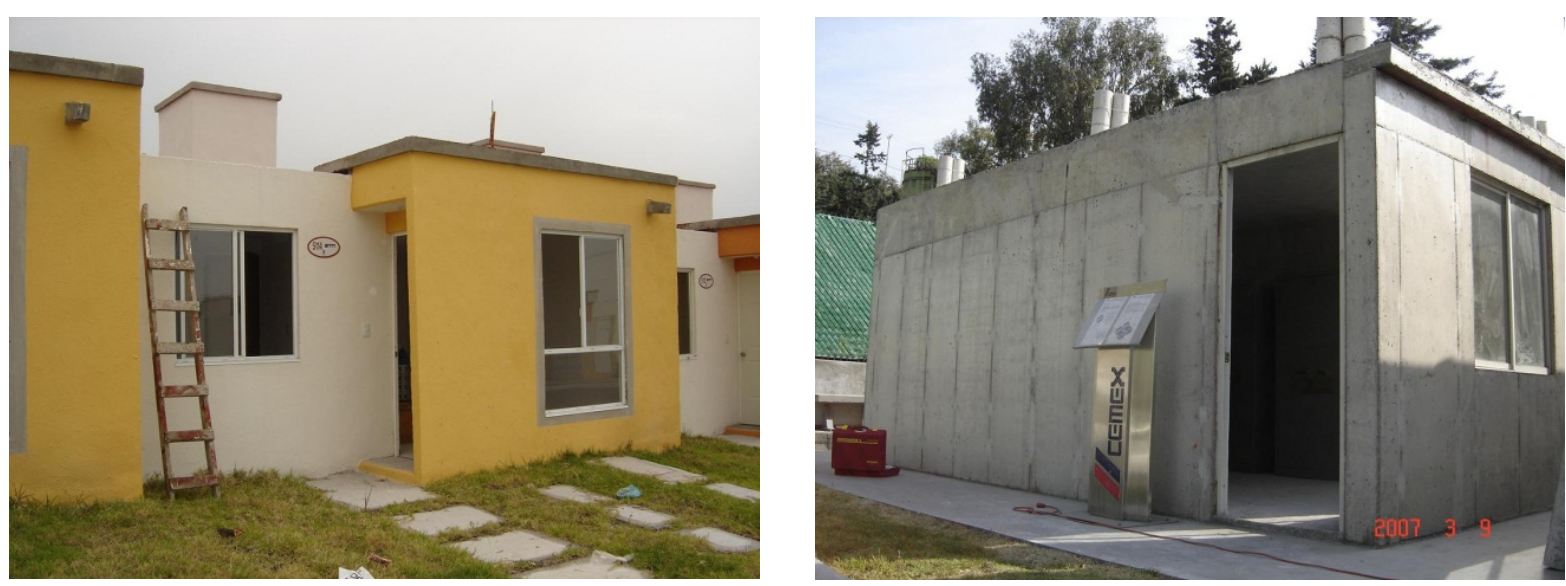

Figure 2 Layout of single-story prototypes: (a) P-1-1, (b) P-2-1.

Two $36 \mathrm{~m}^{2}$ small dwellings made of normalweight concrete (P-2-1N) and lightweight (P-2-1L) concrete were also included. The plan of walls distribution and layout of prototypes P-2-1 are shown in Figures $1 \mathrm{~b}$ and $2 \mathrm{~b}$, respectively. Dwellings P-2-1N and P-2-1L were built to be isolated from other dwellings. 


\subsection{Ambient vibration tests}

In the case of stiff low-rise and low-cost concrete dwelling, which is dominated by the first mode shape associated with the translations in $\mathrm{X}$ or $\mathrm{Y}$ directions, it is probably more appropriate to utilize technique based on ambient vibrations instead of on forced vibrations, since ambient vibration provides reliable results for a reasonable price. In case of higher or heavier structures, it is justified the use of more complicated and more expensive forced vibrations such as forced vibrations, which enable clearer view of the higher modes (Snoj et al., 2012). In this study, the ambient vibration technique was used in order to estimate natural frequencies of low-rise concrete dwellings. The goal of the measurements was also to calibrate a numerical model of the dwellings. As it was mentioned earlier, AVT was carried out in three single-story dwellings only.

Vertical vibrations of floor slabs (out of plane) can be excited by jumping and heavy walking on the slabs. Ambient vibration testing was not carried out by measuring the response under artificialinduced loading. Measurement of ambient vibrations was performed before dwellings were occupied by owners. Furthermore, very poor estimate of the higher modes of the vertical vibrations can be obtained using ambient vibration tests and therefore, only the first two longitudinal modes are considered in this study.

\section{Description of the measuring equipment}

In this study, we used a data acquisition system that allows the simultaneous recording of eight channels located in different points of the structure. Ambient vibrations were measured using highresolution uniaxial acceleration transducers. Measurement of ambient vibrations does not require calibration of all instruments so that they give the same amplitudes when excited by the same base motion. Nor is necessary to find the actual amplitudes recorded, because all that is ever used in determined frequencies is the relative amplitude of the same two instruments at a given frequency (Trifunac, 1972).

Signal conditioners were used to amplify and filter simultaneously outputs of the accelerometers. Because all frequencies that can be used for building analysis lie well below $30 \mathrm{~Hz}$, and to easy data processing, the original records were passed through low-pass filters. Then, channels were connected to computers where analog signal from sensors was transformed into digital signal and saved. A two-channel spectrum analyzer was used to have immediate visual inspection of the vibrations.

\section{Experimental setup}

In this section, the experimental setup is briefly described. In-situ modal analysis has been performed in this study. Practical issues for vibration recordings are the layout measurement, and the frequency and time length of recordings. The number of recorded points depends on the height, complexity and accessibility of the building. The sampling frequency depends on the greatest frequency we want to estimate, practically never more than $30 \mathrm{~Hz}$ for usual buildings (Michel et al., 2008). The time-length of the recorded window should be at least equivalent to 1000 periods of the structure in order to calculate an accurate spectral estimate (Brincker et al., 2003).

The first frequency of the dwellings was roughly estimated to be close to $0.1 \mathrm{~s}$. Therefore, ambient vibrations were recorded simultaneously on all stations during $10 \mathrm{~min}$ for each test, which is long enough with respect to the Brincker et al. (2003) criterion (1000 periods). The data from ambi- 
ent vibrations was acquired by using a sampling rate of $200 \mathrm{~Hz}$ (200 discrete points/sec). Two series of measurements were done.

To monitor the dwellings, a set of six accelerometers was used in several set-up positions, each one of which was designed to identify a particular vibration mode. Two horizontal axes of the sensors were oriented along the main directions of the dwellings. Transverse, T, and longitudinal, L, directions correspond to $\mathrm{X}$ and $\mathrm{Y}$ directions in the plans of the dwellings (see Figure 1). To measure the translational modes, all instruments would be placed in the center of the structural cross-section or in the center of torsion. In this study, the center of torsion was known at the time these tests were performed, and therefore, all instruments were placed in the center of torsion for measuring translational modes.

To obtain translational frequencies, the measurements of the dwellings were conducted in the following way. Acceleration transducers were located on the following points: two accelerometers at the center of the top slab (AC), two accelerometers permanently located at the center of the firstlevel slab (base) and two accelerometers permanently located on the ground close to the dwellings (CL).

\section{Data processing}

Many different techniques exist to determine the modal parameters (frequencies and modal shapes) of the considered system. Procedures based on random vibration theory are commonly used (MuriaVila et al., 2001). When the frequencies are the parameter to be assessed, the easiest and most widely used is the peak-picking (PP) method. It consists of picking the value of the frequency peaks of the average spectrum (Michel et al., 2008). With a very good precision, the modal frequencies and shapes of the coupled soil-structure system can be simply deduced by peak-picking. The same procedure applies for the calculation of the modal transfer functions (MTF) of the structure (Hans et al., 2005).

In this study, the peak-picking method was used for identifying frequencies of vibration of the dwellings. The signals were processed with several usual techniques performed in both spectral and time domain. The average power spectrum (APS) of records at the center of torsion of the top slab was used for identifying fundamental frequencies of vibration in the transverse $(\mathrm{T})$ and the longitudinal (L) directions. APS was used instead of MTF because the structural system of the concrete wall dwellings is sufficiently stiff to facilitate identification of inter-story movements. APS for the three dwellings are given in Figures 3,4 and 5. Bell shape curves with the peaks corresponding to the location of natural frequencies can be observed from these figures. Values of fundamental frequencies of each dwelling are indicated in the figures.

The shape of the curves and the intervals of maximum ordinates in Figures 3, 4 and 5 vary from one event to another. For instance, maximum ordinate of ambient vibrations was about $10^{-6} \mathrm{~g}$ for P-1-1 dwelling (Figure 3) and $10^{-4} \mathrm{~g}$ for P-2-1 dwellings (Figures 4 and 5). Furthermore, for some events, more than one significant peak appeared around a modal frequency. 


\subsection{Numerical modeling}

When dynamic analysis is used through the design process, periods of structures are normally computed from a numerical model rather than from code equations. Computer-assisted models were used herein for estimating the fundamental periods of vibration of single- and two-story typical dwellings. Wide-column and finite element linear models were used for modeling the prototype dwellings. Walls layouts of typical dwellings were shown in Figure 1.

Although we did not detect any visible structural damage of the dwellings, test data acquired during shaking-table testing of concrete walls for low-rise dwellings (Carrillo and Alcocer, 2012) revealed that nonlinearity occurs at load levels lower than those associated to onset of reinforcement yielding. To better grasp this nonlinear behavior, Carrillo and Alcocer (2012) have recommended to include concrete cracking in stiffness calculations by applying a reduction factor equal to 0.5 to both shear and flexural deformations. In the following, a brief description of the linear modeling parameters are given; the details about the modeling are completely omitted.
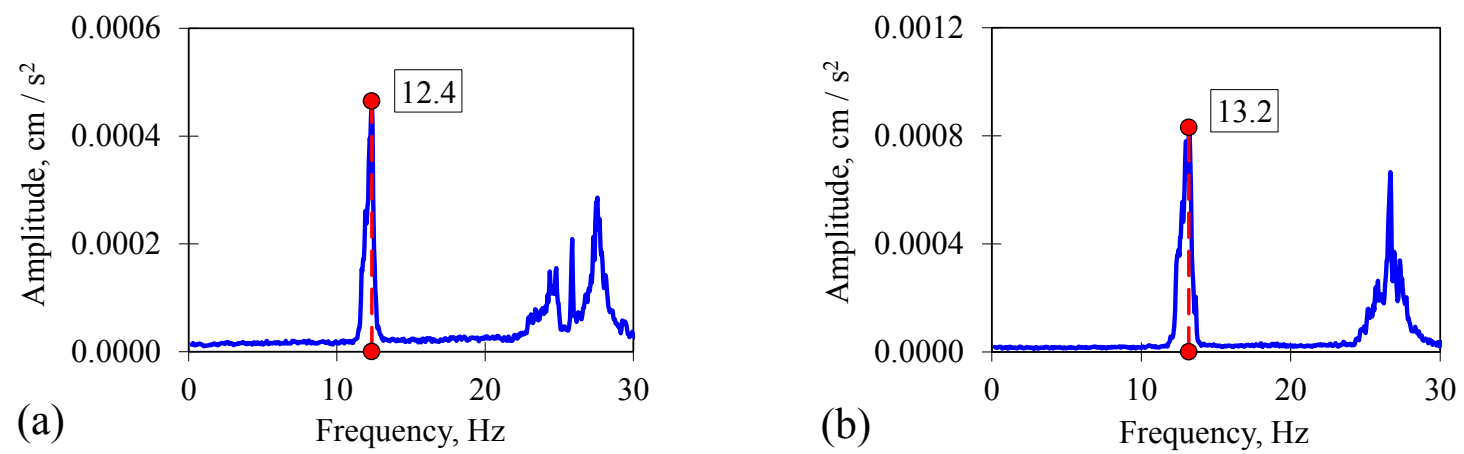

Figure 3 Results of APS for P-1-1 dwelling: (a) AC-T, (b) AC-L.

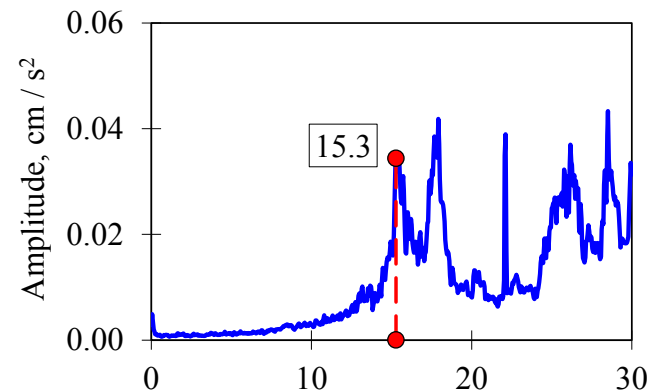

(a)

Frequency, $\mathrm{Hz}$

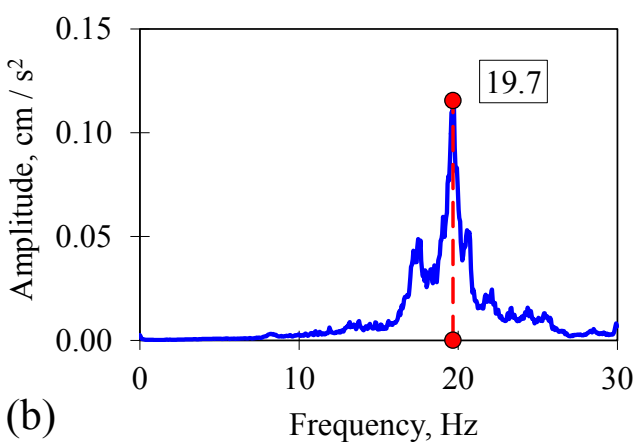

Figure 4 Results of APS for P-2-1N dwelling: (a) AC-T, (b) AC-L. 

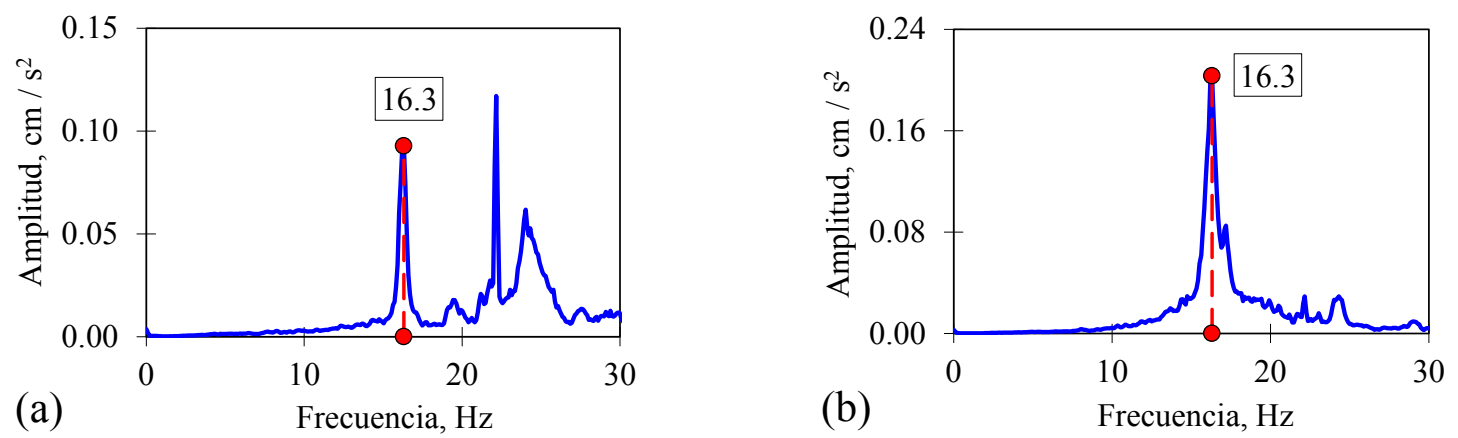

Figure 5 Results of APS for P-2-1L dwelling: (a) AC-T, (b) AC-L.

\section{Modeling procedures}

The following common rules were considered for modeling purposes: (a) both shear area and bending moment of inertia of wall cross section were calculated under the assumption of cracked sections according to the cracking factors recommended by Carrillo and Alcocer (2012), (b) floor diaphragms were assumed to be rigid in their own plane, so that three degrees of freedom at each floor level resulted (translations in two orthogonal directions and rotation around the vertical axis), (c) story mass was lumped at the center of mass of slabs, (d) the self-weight and the dead load of the dwellings were computed according to typical recommendations of building codes and were considered to be as realistic as possible at the time of the experiments, (e) dynamic spectral analysis considered $5 \%$ of accidental eccentricity and were performed according to usual provisions of building codes, and (f) a commercial computer analysis program (SAP 2000, 2005) was used for assembling the linear structural models.

In the case of finite element models (FEM), two-dimensional plane stress elements used. Considering that the fragments of walls are usually rectangles, four-node (quadrilateral) shell elements that reflect both membrane and bending actions were employed. This element was selected because it has six degrees of freedom at each node and is widely used for the analysis of planar and nonplanar shear wall assemblies. A sensitivity study was carried out to determine the dimension of square elements to be used for modeling the global behavior of low-rise concrete wall housing. The dimension of square elements varied between that equivalent to one and five times the wall thickness (100-mm and $500 \mathrm{~mm}$ ). Minor variations were observed for dimensions lower than three times the wall thickness. Therefore, walls were modeled using 250-mm square elements with linear properties. In the case of wide column analogy (WCA), walled structures were modeled through equivalent wide-columns and rigid beams, thus forming a three-dimensional frame system. Frame elements had six degrees of freedom at both ends (three translations and three rotations).

All the tested dwellings are founded on shallow foundations. The soil is granular with good mechanical properties. To compare predicted and measured periods, equivalent linear stiffness to define soil springs were used for modeling the soil-structure interaction of concrete dwellings having a shallow foundation system. 
Materials properties

Concrete cores were obtained from walls of P-2-1 single-story dwellings only. Testing on concrete cores provided information about the compressive strength, modulus of elasticity and Poisson ratio of concrete, being 19.5 MPa, $12250 \mathrm{MPa}$ and 0.2 , respectively.

Destructive tests of concrete were not allowed to perform in both P-1-1 single story dwelling and P-1-1 two-story dwelling. In the absence of destructive in-situ tests of walls of these prototypes, mechanical properties of concrete were assumed to be those used in design. In effect, compressive strength, modulus of elasticity and Poisson ratio were equal to $15 \mathrm{MPa}, 9600 \mathrm{MPa}$ and 0.2 , respectively. A 3-D view of finite element models of prototype dwellings is shown in Figure 6.
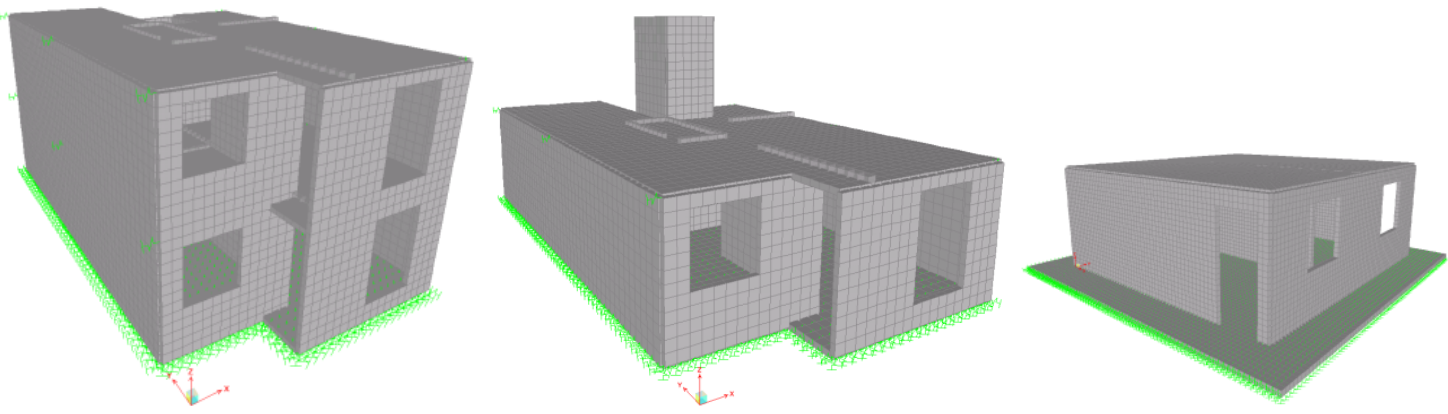

Figure 6 Finite element models of prototype dwellings: (a) P-1-2, (b) P-1-1, (c) P-2-1.

\section{RESULTS AND DISCUSSION}

Assessment of seismic performance of existing low-rise concrete dwellings is affected by many uncertainties, which are difficult to evaluate. The effect of uncertainties can be reduced by the use of non-destructive experimental techniques. One of the possibilities to reduce modeling uncertainty is to measure ambient vibrations for the purpose of estimating the natural periods of vibration of the structure. In this study, sensitivity studies were done in order to calibrate elastic structural models of concrete dwellings based on the estimated periods of vibration obtained from the ambient vibration measurements.

\subsection{Ambient vibration tests}

As discussed earlier, the first two natural frequencies associated to translational modes of singlestory concrete dwellings were evaluated by utilizing peak picking (PP) method. The procedure is illustrated in Figures 3, 4 and 5, and is based on measurement of ambient vibrations. Fundamental periods of vibration (inverse of the frequency) identified during ambient vibration tests $\left(\mathrm{T}_{\mathrm{AVT}}\right)$ are presented in Table 2. Transverse, T, and longitudinal, L, directions correspond to X and Y directions in the plans of the dwellings. Note that we preferred to report natural periods of vibration rather than natural frequencies since this is more common for structural engineers. 
Table 2 Fundamental periods of vibration of single- and two-story dwellings.

\begin{tabular}{|c|c|c|c|c|c|c|c|c|}
\hline \multirow{2}{*}{ Stories } & \multirow{2}{*}{ Type } & \multirow{2}{*}{ Direction } & \multicolumn{3}{|c|}{$\mathrm{T}, \mathrm{s}$} & \multirow{2}{*}{$\begin{array}{c}\mathrm{T}_{\mathrm{FEM}} / \\
\mathrm{T}_{\mathrm{AVT}} \\
\end{array}$} & \multirow{2}{*}{$\begin{array}{c}\mathrm{T}_{\mathrm{WCA}} / \\
\mathrm{T}_{\mathrm{AVT}} \\
\end{array}$} & \multirow{2}{*}{$\begin{array}{c}\mathrm{T}_{\mathrm{FEM}} / \\
\mathrm{T}_{\mathrm{WCA}} \\
\end{array}$} \\
\hline & & & $\mathrm{AVT}$ & FEM & WCA & & & \\
\hline \multirow{6}{*}{ Single } & \multirow{2}{*}{ P-1-1 } & $\mathrm{T}$ & 0.081 & 0.081 & 0.089 & 1.00 & 1.10 & 0.92 \\
\hline & & $\mathrm{L}$ & 0.076 & 0.073 & 0.094 & 0.96 & 1.23 & 0.77 \\
\hline & \multirow{2}{*}{ P-2-1N } & $\mathrm{T}$ & 0.065 & 0.066 & 0.083 & 1.02 & 1.26 & 0.80 \\
\hline & & $\mathrm{L}$ & 0.051 & 0.055 & 0.072 & 1.09 & 1.42 & 0.77 \\
\hline & \multirow{2}{*}{ P-2-1L } & $\mathrm{T}$ & 0.061 & 0.058 & 0.071 & 0.94 & 1.17 & 0.81 \\
\hline & & $\mathrm{L}$ & 0.061 & 0.049 & 0.065 & 0.81 & 1.06 & 0.76 \\
\hline \multirow{4}{*}{ Two } & \multirow{2}{*}{---} & $\mathrm{L}$ & --- & 0.121 & 0.152 & --- & --- & 0.80 \\
\hline & & $\mathrm{T}$ & --- & 0.110 & 0.119 & --- & --- & 0.93 \\
\hline & \multicolumn{5}{|c|}{ Mean } & 0.97 & 1.21 & 0.82 \\
\hline & \multicolumn{5}{|c|}{ Coefficient of variation, $\%$} & 9.0 & 9.9 & 7.3 \\
\hline
\end{tabular}

Low periods of vibration of the studied structures (between 0.05 and $0.15 \mathrm{~s}$ ) were expected since residential concrete dwellings with thin walls $(100 \mathrm{~mm})$, which represent large percentage of the dwelling's plan (total wall density around $10 \%$ ), are very stiff. In the single-story dwellings, the period of the first mode was characterized by translation in $\mathrm{T}$ direction while the period of the second mode was characterized by translation in L direction (see Table 2).

In urban areas, the dwellings are often very close to each other. As shown earlier, low-rise concrete dwellings are commonly separated from adjacent dwellings by $3 \mathrm{~cm}$ gaps filled with polystyrene that runs only over a small part of the longitudinal façade. Nevertheless, their possible dynamic mutual influences are not commonly taken into account. It should be noted that the magnitude of the ambient motion is very small compared to the thickness of the structural joints (which concerns only a small part of the facade) which therefore do not play any significant role in the dynamics (Hans et al., 2005).

In terms of the effect of soil-structure interaction, the ambient vibration measurements naturally lead to the modal characteristics of the structure coupled with the soil. As presented earlier, all the tested dwellings are founded on shallow foundations and the soil is granular with good mechanical properties. When the soil presents good characteristics, a weak contribution of the soil-structure interaction might be expected, particularly in the case of ambient vibrations due to soil motions. Consequently, the base motion is almost identical to the incident motion, and therefore, the modal parameters of the structure coupled with the soil are close to those of the structure founded on a rigid basement, at least for the first modes (Hans et al., 2005). In addition, for code-based seismic design, fixed-base is commonly assumed. However, to compare predicted and measured periods, equivalent linear stiffness to define soil springs were used in this study for modeling the soilstructure interaction of concrete dwellings having a shallow foundation system. 


\subsection{Numerical modeling}

The goal of the measurements was to calibrate numerical models of the dwellings. Sensitivity studies were conducted through linear models using finite element method and wide-column analogy. The purpose of the sensitivity studies was to modify properties of numerical models in order to assess suitably the dynamic behavior of the dwellings. For numerical modeling, it is important to understand which components of the structure have structural relevance. In summary, structural parameters described in section 3.3 led to an adequate correlation between measured and calculated response from mathematical models. Periods of vibration obtained from finite element method $\left(\mathrm{T}_{\mathrm{FEM}}\right)$ and wide-column analogy $\left(\mathrm{T}_{\mathrm{WCA}}\right)$ of single- and two-story dwellings are shown in Table 2. Ratios $\mathrm{T}_{\mathrm{FEM}} / \mathrm{T}_{\mathrm{AVT}}, \mathrm{T}_{\mathrm{WCA}} / \mathrm{T}_{\mathrm{AVT}}$ and $\mathrm{T}_{\mathrm{FEM}} / \mathrm{T}_{\mathrm{WCA}}$ are included in the table.

Mean value of the ratios $\mathrm{T}_{\mathrm{FEM}} / \mathrm{T}_{\mathrm{AVT}}(0.97)$ and $\mathrm{T}_{\mathrm{WCA}} / \mathrm{T}_{\mathrm{AVT}}$ (1.21) indicates that the two methodologies may be used for assessing the period of vibration of low-rise concrete dwellings. However, when comparing $\mathrm{T}_{\mathrm{FEM}}$ and $\mathrm{T}_{\mathrm{WCA}}$ with those measured using AVT, it is apparent in Table 2 that periods of vibration obtained from FEM are closer to those measured during AVT. In addition, ratio $\mathrm{T}_{\mathrm{FEM}} / \mathrm{T}_{\mathrm{WCA}}$ shows that $\mathrm{T}_{\mathrm{WCA}}$ was $22 \%(1 / 0.82)$ larger, on the average, than $\mathrm{T}_{\mathrm{FEM}}$. This trend stems from the fact that WCA failed to suitably reproduce shear deformations of low-rise walls. The difference is also credited to the oversimplification in WCA for properly modeling border conditions of concrete walls ends, particularly in lengthened walls.

In the two-story dwelling, the period of the first mode was characterized by translation in $\mathrm{L}$ direction while the period of the second mode was characterized by translation in $\mathrm{T}$ direction. Because AVT could not be performed over the two-story prototype, fundamental periods were obtained exclusively from finite element method $\left(\mathrm{T}_{\mathrm{FEM}}\right)$ and wide-column analogy $\left(\mathrm{T}_{\mathrm{WCA}}\right)$. However, measured results were crucial to calibrate mathematical models not only of single-story but also of two-story dwellings. Similarly to single-story dwellings, $\mathrm{T}_{\mathrm{WCA}}$ was $25 \%(1 / 0.80)$ and $8 \%(1 / 0.93)$ larger than $\mathrm{T}_{\mathrm{FEM}}$ in $\mathrm{L}$ and $\mathrm{T}$ directions, respectively (see Table 2). A period of vibration of $0.12 \mathrm{~s}$, which was calculated from FEM, can be considered valid for the two-story dwelling.

\subsection{Recommendations to build numerical models}

Currently, there are several numerical tools for modeling concrete structures. Using one of these commercial computer programs, it is not a guarantee that results show the actual behavior of the structure under a particular action. Accuracy of results strongly depends on criterion and capacity of the structural engineer both to include suitably the geometrical properties, restraints and loads in the models, and to analyze and understand the results obtained from the software. Based on results of this study, particular recommendations to build numerical models for assessing the elastic behavior of low-rise concrete wall dwellings are proposed in this section.

\section{Parametric technique}

Although it is relatively simple to build numerical models using the wide-column analogy, this technique fails in both reproducing shear deformations of low-rise concrete walls and modeling of particular geometry and border conditions of walls. When using finite element models, these drawbacks and oversimplifications are solved and the accuracy of results is improved. Although higher

Latin American Journal of Solids and Structures 11 (2014) 488 - 503 
knowledge and time-consuming are required, it is recommended to use the finite element method for modeling the elastic behavior of low-rise concrete wall dwellings. In this case, four-node plane stress shell elements that reflect both membrane and bending actions should be employed. This twodimensional element has six degrees of freedom at each node. Considering that the fragments of walls are usually rectangles, it is recommended to use $250-\mathrm{mm}$ square elements with linear properties for modeling the walls.

\section{Mechanical properties and cracking of concrete}

To estimate the period of vibration that leads to conservative seismic demands in terms of forces and displacements, it is necessary to consider variations of modulus of elasticity of concrete. It is recommended to use equations suggested by Carrillo et al. (2013), which are proposed in terms of the type of concrete of low-cost dwellings.

To include nonlinearity of concrete that occurs at load levels lower than those associated to onset of reinforcement yielding, it is recommended to include concrete cracking factors proposed by Carrillo and Alcocer (2012), that is, by applying a reduction factor equal to 0.5 to both shear and flexural deformations in stiffness calculations.

\section{Floor diaphragm and story mass for dynamic analysis}

Several floor systems used for construction of low-rise dwellings should be considered as flexible diaphragms. Flexibility of floor diaphragm is a condition that should be checked because the response under lateral loads of a structure with rigid diaphragms in their own plane can be significantly different of a structure with flexible diaphragm. Considering the structural system (low-rise shear walls), geometry (box-type) and spans (between $1 \mathrm{~m}$ and $4 \mathrm{~m}$ ) of low-rise concrete wall dwellings, it is considered that the assumption of rigid diaphragm is appropriate. In this case, three degrees of freedom at each floor level are obtained (translations in two orthogonal directions and rotation around the vertical axis).

When floor diaphragms are modeled as rigid in their own plane, a practical assumption for dynamic analysis consists in lumping the masses using a master join. This joint should be located in the center of mass of the floor slab and serves to lump the translational and rotational masses of the considered floor.

\section{Joint between adjacent dwellings}

Low-rise concrete dwellings are commonly built close to each other and separated from adjacent dwellings by gaps filled with polystyrene. To avoid including during modeling the effects of interaction between dwellings, proper operation of the joint should be guaranteed during lifetime of the dwellings, for instance, that the joint runs over the full length of the façade in contact.

\section{Soil-structure interaction}

Contribution of the soil-structure interaction depends of the soil characteristics. Considering the height, the structural system, and the shallow foundation system (strip footings made of RC beams that support a floor slab) of low-rise concrete wall dwellings, the equivalent linear stiffness to define soil springs is a reliable technique for modeling the soil-structure interaction of this type of dwell- 
ings. Initially, the foundation slab should be modeled by means of finite elements linked by a rigid diaphragm. Based on the tributary area of each joint in the slab, the stiffness of the vertical spring located at the joint is computed. According to Delgado (1998), the $30 \%$ of the vertical stiffness can be used for horizontal springs. However, it is noteworthy that fixed-base is commonly assumed for code-based seismic design of low-rise concrete wall housing.

\subsection{Limitations of results}

Theoretical studies of earthquake-resistant structures are more concerned with calculations based on elasto-plastic and other non-linear force-deflection relationships. During these large, partially damaging motions, modes and natural periods of the structure will be different from these determined by the linear theory or by experiments based on low-level vibrations.

Ambient vibration testing is based on small levels of excitation compared to strong earthquake ground motions, and gives information that is applicable only for theory of elasticity in structural analysis. There is no doubt that the low level of the shaking during ambient vibrations only gives relevant information on the elastic behavior of the dwellings. However, the small-amplitude experimental determinations of structural properties are invaluable because they not only offer a sound basis for rational improvements in the existing vibration theory but also serve as reference points for more complete calculations (Trifunac, 1972). In addition, the experimental elastic behavior of dwellings can be formalized in a complete model using modal analysis of ambient vibrations. In general, measurements of ambient vibrations on real dwellings may be actually of interest for seismic assessment, because they represent the effective dynamic behavior before significant structural damages. This technique has been widely used in civil engineering applications to understand the linear behavior of structures in terms of vibration modes (Hans et al., 2005; Michel et al., 2008).

\section{CONCLUSIONS}

In order to perform code-based seismic design of a dwelling, the first step is to build the linear numerical model of the structure for estimating dynamic properties. In this study, the fundamental periods of vibration of typical low-rise concrete wall dwelling units were evaluated by means of both conventional spectral analysis of ambient vibration test, and numerical models using the widecolumn analogy and the finite element method. In the ambient vibration test, which can easily be performed, vibrations generated due to ambient conditions were useful to understand the structural behavior associated to displacement demands of low amplitudes. Ambient vibrations recorded during in-situ tests of dwellings were processed for estimating the periods of vibration for the first and second mode. Numerical models were calibrated so that good correlation between measured and calculated response was attained. Both system identification methodologies were also used to validate the applicability of parametric techniques for modeling of low-rise concrete wall dwellings.

The difference between the numerically computed and experimentally obtained mean natural periods of vibration was $3 \%$ when finite element method is used. However, in the case of wide column analogy, the numerically computed mean period of vibration is around $21 \%$ larger than the mean period of vibration from the experiments. This is the consequence of deficient reproducing of shear deformations of low-rise walls and the oversimplification in wide-column analogy for properly

Latin American Journal of Solids and Structures 11 (2014) 488 - 503 
modeling border conditions of concrete walls ends, particularly in lengthened walls. Recommendations to build numerical models for assessing the elastic behavior of low-rise concrete wall dwellings, such as mechanical properties and cracking of concrete, type of floor diaphragm, story mass for dynamic analysis, joint between adjacent dwelling and soil-structure interaction, were presented and discussed.

\section{References}

Brincker, R., Ventura, C., Andersen, P. (2003). Why output-only modal testing is a desirable tool for a wide range of practical applications, Proceedings of 21st International Modal Analysis Conference, Kissimmee, FL, USA.

Carrillo, J., Alcocer, S., Aperador, W. (2013). Mechanical properties of concrete for low-cost dwellings. Journal of Ingeniería, Investigación y Tecnología 14:285-298.

Carrillo, J., Alcocer, S. (2012). Seismic performance of concrete walls for dwellings subjected to shaking table excitations. Journal of Engineering Structures 41:98-107.

Charney, F., Darling, S., Eatherton, M. (2012). Seismic performance of very short period structures, Proceedings of 15th World Conference on Earthquake Engineering, Lisbon, Portugal, Paper 5015.

Computer and Structures (2005). Static and dynamic finite element analysis of structures - SAP2000 V10.01. Berkeley, CA.

De Biasio, M., Grange, S., Dufour, F. (2012). The role of model calibration in seismic FE analysis: the case study of an old reinforced concrete structure by using ambient vibration noise modal analysis, Proceedings of 15 th World Conference on Earthquake Engineering, Lisbon, Portugal, Paper 3547.

Delgado, M. (1998). Soil-structure interaction, Colombian School of Engineering, Bogotá, Colombia (in Spanish). Ditommaso, R., Vona, M., Mucciarelli, M., Masi, A. (2010). Identification of building rotational modes using an ambient vibration technique, Proceedings of 14th European Conference on Earthquake Engineering, Macedonia.

Hans, S., Boutin, C., Ibraim, E., Roussillon, P. (2005). In situ experiments and seismic analysis of existing buildings. Part I: Experimental investigations. Journal of Earthquake Engineering and Structural Dynamics 34:15131529 .

Michel, C., Gueguen, P., El-Arem, S., Mazars, J., Kotronis, P. (2010). Full-scale dynamic response of a RC building under weak seismic motion using earthquake recordings, ambient vibration and modeling. Journal of Earthquake Engineering and Structural Dynamics 39:419-441.

Michel, C., Gueguen, P., Bard, P. (2008). Dynamic parameters of structures extracted from ambient vibration measurements: an aid for the seismic vulnerability assessment of existing buildings in moderate seismic hazard regions. Journal of Soils Dynamics and Earthquake Engineering 28:593-604.

Muria-Vila, D., Rodríguez, G., Zapata, A., Toro, A. (2001). Seismic response of a twice-retrofitted building. Journal of Earthquake Technology 38:67-92.

Snoj, J., Osterreicher, M., Dolsek, M. (2012). Experimentally supported modeling of an existing masonry building by measuring ambient and forced vibrations, Proceedings of 15th World Conference on Earthquake Engineering, Lisbon, Portugal, Paper 2231.

Trifunac, M. (1972). Comparisons between ambient and forced vibration experiments. Journal of Earthquake Engineering and Structural Dynamics 1:133-150.

Ward, H. (1977). Experimental techniques and results for dynamic tests on structures and soils, Proceedings of 6th World Conference on Earthquake Engineering, New Delhi, India. 